\title{
Computational models of reinforced concrete ribbed floor
}

\author{
Przemysław Czumaj ${ }^{1,}$, , Stawomir Dudziak $^{1}$, and Zbigniew Kacprzyk ${ }^{1}$ \\ ${ }^{1}$ Warsaw University of Technology, ul. L. Kaczyńskiego 16, 00-637 Warszawa, Poland
}

\begin{abstract}
This paper describes differences between models of a rectangular shaped reinforced concrete floor with ribs, commonly used by structural designers. Comparison analysis proves significant differences in result obtained from different models. Incompatibility is shown both in static as well as in modal analysis.
\end{abstract}

\section{Introduction}

The ease of creating computational models of complex structures encourages structural designers to reach for advance models, which are almost impossible to verify with simple methods. As BIM process increases its popularity, [1,2], number of 3D projects, with complex models containing beams and shell type of elements, [3], is getting higher. Such models, often without even a thought, are later subject of advance computational analysis.

In this paper RC floor with ribs (Fig. 1) will be analysed. Most common in practical uses, computational models will be discussed.

Static calculation have been performed for one load case only - uniform planar load, value of $25.0 \mathrm{kN} / \mathrm{m}^{2}$. In case of model with beam type element only, uniform linear load, value of $40 \mathrm{kN} / \mathrm{m}\left(1.6 \mathrm{~m} \cdot 25 \mathrm{kN} / \mathrm{m}^{2}=40 \mathrm{kN} / \mathrm{m}\right)$ have been applied. Structure self-weight has not been applied. Material taken: concrete C30/37. In modal analysis, consisted mass matrix has been used.

Presented work is part of wider problem of computational analysis model of engineering structures.

\footnotetext{
* Corresponding author: p.czumaj@il.pw.edu.pl
} 


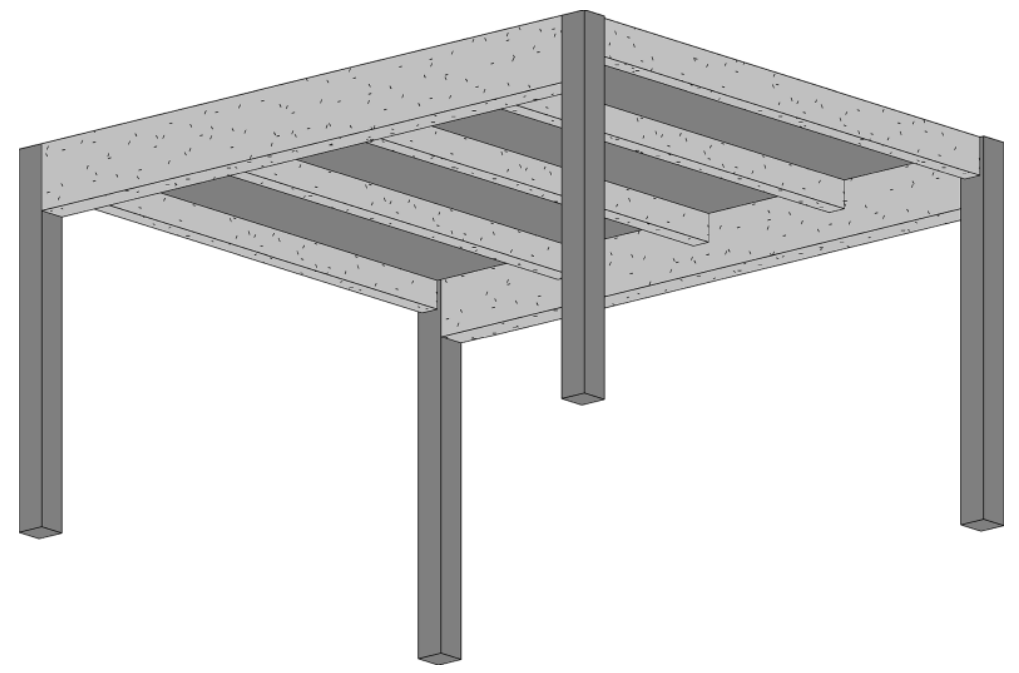

Fig. 1. Analysed RC floor with ribs.

\section{Computational models}

For purpose of this paper, three types of models have been made.

2.1 Complete floor models, containing shell (slab) and beam (ribs and columns) types of elements (Fig. 2), called "F-S-B".

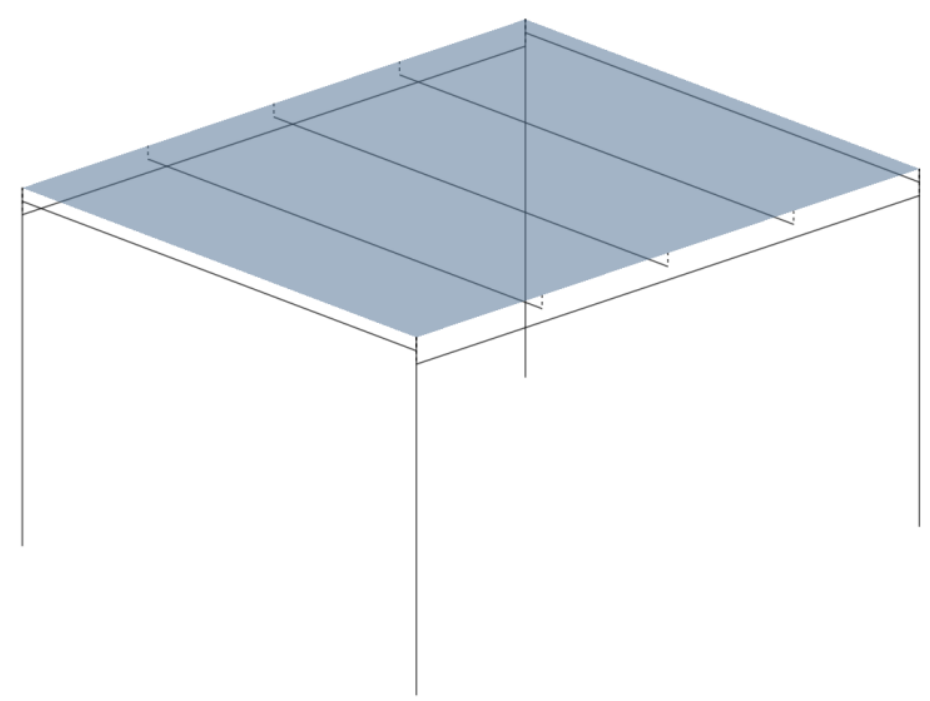

Fig. 2. Model consisting of shell (slab) and beam (ribs and columns) types of elements.

This type of model consists of three subtypes: each with different style of beams offsets from the slab (Fig. 3). 

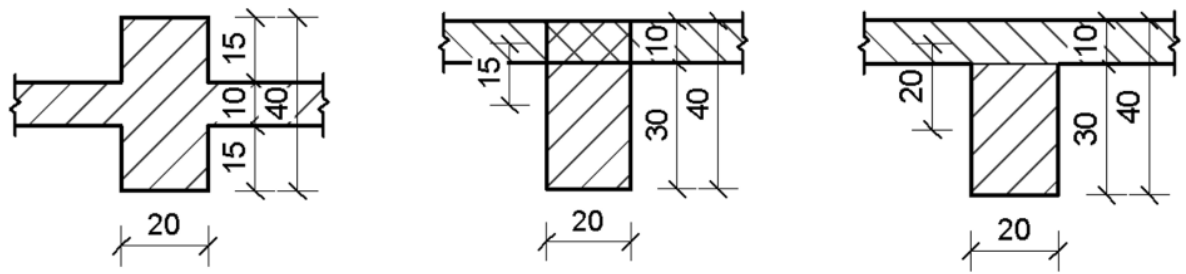

Fig. 3. Options of offsets between beam and slab for each subtype of F-S-B model.

\subsection{Models of interior beam with flange, containing shell (slab) and beam (rib)} types of elements (Fig. 4), called "I-S-B".

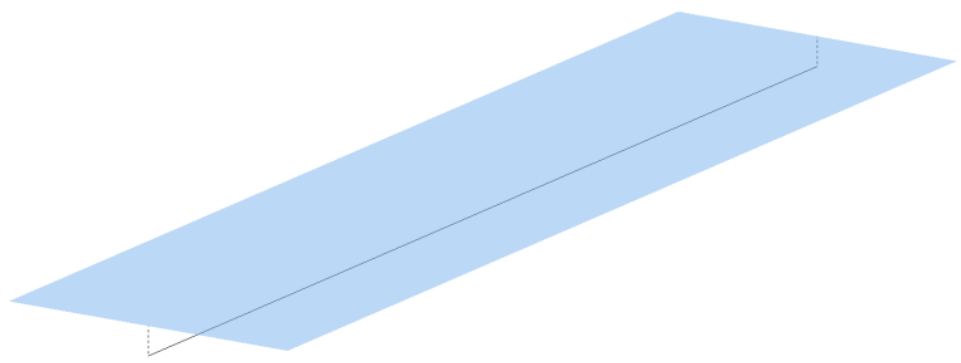

Fig. 4. I-S-B model.

This type of model has the same three subtypes as model F-S-B, with different offset options (Fig. 3).

\subsection{Solid model of complete floor called "S-F".}

Whole model has been computed in complex stress state with 3D solid finite elements C3D20R (calculations have been computed in Abaqus system). This model is treated as a benchmark.

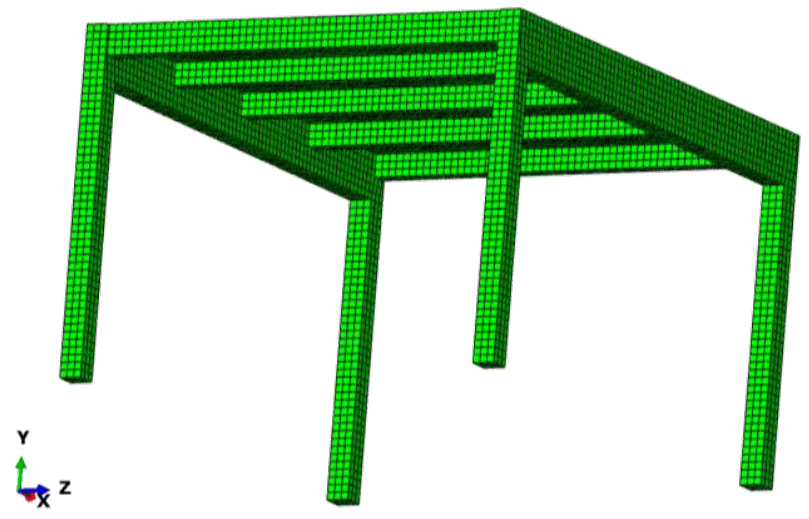

Fig. 5. "S-F" model. 


\subsection{Solid model of interior beam with flange (Fig. 8), called "S-l".}

This model contains interior beam taken out of the floor with effective flange width. It has been computed in the triaxial stress state with 3D solid type of elements. This model is treated as a benchmark for 2.2 and 2.3. It has been analysed because of its simplicity followed by common use by engineers.

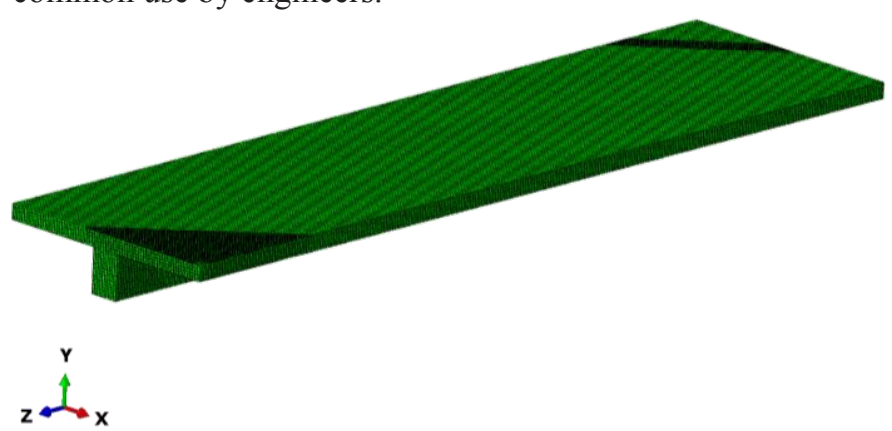

Fig. 6. S-I model.

\subsection{Remarks}

\subsubsection{Finite element of beam with offset.}

For model consisting of beam and shell types of elements, model prismatic beam finite element, with nodes off the axis (Fig. 7) is be used. Between element's ends and defined nodes, rigid links with infinite stiffness is created. Full translation and rotation compatibility between beam and nodes is preserved.

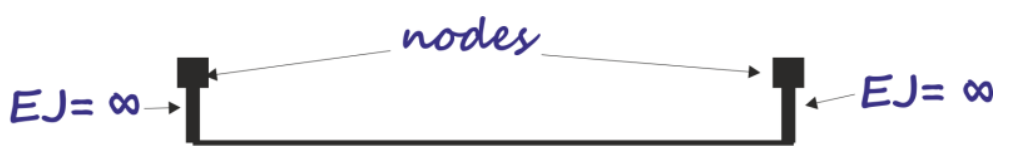

Fig. 7. Beam finite element with offset.

\subsubsection{Accuracy analysis.}

For all models accuracy analysis has been made according to finite elements mesh.

\subsection{Supports}

\subsubsection{F-S-B}

Columns have been fully supported at their base, 6 degrees of freedom have been blocked.

\subsubsection{I-S-B}

Beam have been supported at its ends. Translation in horizontal directions have been removed as well as rotation over beam axis. Flange sides had rotation around beam axis and horizontal translations blocked as well. 


\subsubsection{S-F}

In the supports, the column cross-section has been made non-deformable by introducing coupling. In the reference points, all six degrees of freedom have been blocked.

\subsubsection{S-I}

In the supports, the beam cross-section has been made non-deformable by introducing coupling. In the reference points, translational degrees of freedom and rotation around axis $\mathrm{Z}$ and $\mathrm{Y}$ have been blocked. The flange side surfaces has had translation in the $\mathrm{X}$ direction blocked.

\section{Results from static analysis}

Table 1 shows maximum deflections acquired from models F-S-B and I-S-B in three subtypes (Fig. 3) together with reference values obtained from models S-F and S-I. Relative values to F-S-B model have been added, considering deflections of primary beams. Relative values from row 1' should have been compared to value in row 2 .

Table 1. Maximum deflections [cm].

\begin{tabular}{|l|l|c|c|c|c|}
\hline No. & Model & Option I & Option II & Option III & $\begin{array}{c}\text { Reference } \\
\text { value }\end{array}$ \\
\hline 1 & F-S-B & 2.08 & 1.27 & 1.13 & 1.26 \\
\hline 1 & F-S-B (relative) & 1.31 & 0.79 & 0.61 & 0.73 \\
\hline 2 & I-S-B & 1.70 & 0.87 & 0.90 & 0.90 \\
\hline
\end{tabular}

a)

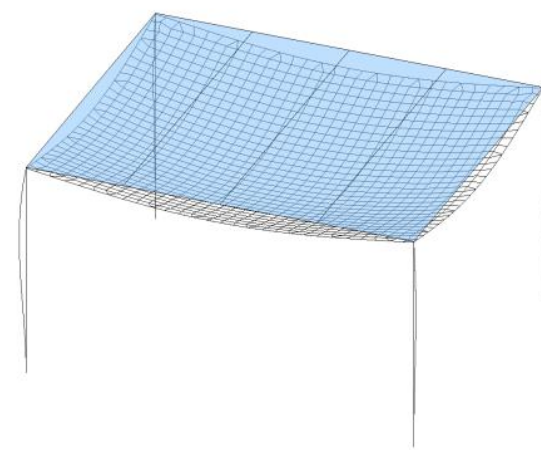

b)

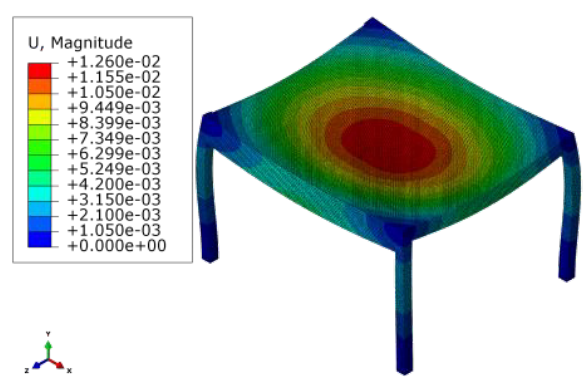

Fig. 8. a) F-S-B model deformation, b) S-F model deformation 
a)

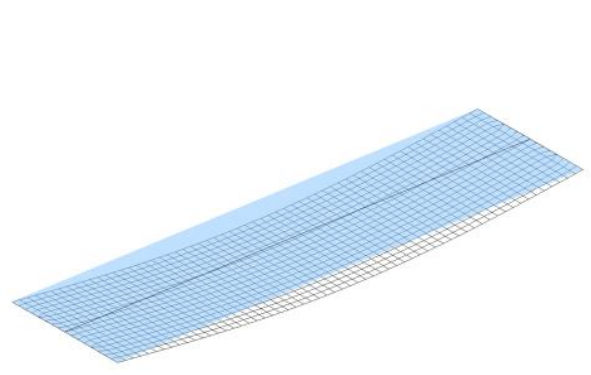

b)

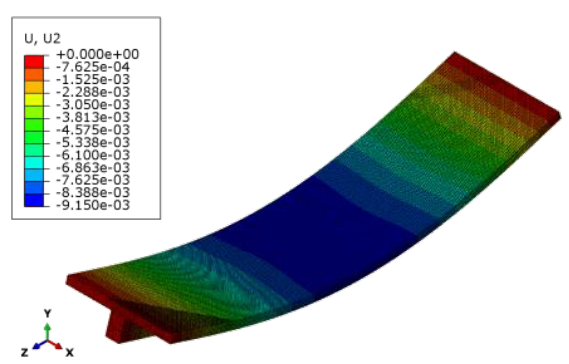

Fig. 9. a) I-S-B model deformation, b) S-I model deformation

\subsection{Convergence analysis}

\subsubsection{S-F reference model}

For S-F model convergence analysis have been performed for different finite elements size. Maximum deflections have been obtained as follows:

- element size of $10 \mathrm{~cm}$ (195000 degrees of freedom $)-1.258 \mathrm{~cm}$

- element size of $7 \mathrm{~cm}$ (552 000 degrees of freedom) $-1.259 \mathrm{~cm}$

- element size of $5 \mathrm{~cm}$ (1 296000 degrees of freedom) $-1.260 \mathrm{~cm}$

\subsubsection{S-I reference model}

For S-I model, deflections took values:

- element size of $10 \mathrm{~cm}$ (8 000 degrees of freedom $)-0.97 \mathrm{~cm}$

- element size of $5 \mathrm{~cm}$ (47 000 degrees of freedom $)-0.92 \mathrm{~cm}$

- element size of $2 \mathrm{~cm}$ (591000 degrees of freedom) $-0.90 \mathrm{~cm}$

\section{Results from modal analysis}

Same computational models as in static have been taken into modal analysis. The only difference has been made in I-B model - the beam has been divided into shorter elements to receive more modes.

Results have been collected in tables below for a few normal modes of transversal slab vibration.

Table 2. First normal mode frequency [Hz] (numbers in brackets stands for mode number acquired from computational system)

\begin{tabular}{|l|c|c|c|c|c|}
\hline No. & Model & Option I & Option II & Option III & Reference value \\
\hline 1 & F-S-B & $3.86(2)$ & $3.98(3)$ & $4.05(3)$ & $13.83(4)$ \\
\hline 2 & I-S-B & $11.21(1)$ & $15.66(1)$ & $16.07(1)$ & $15.88(1)$ \\
\hline
\end{tabular}

Table 3. Second normal mode frequency $[\mathrm{Hz}]$

\begin{tabular}{|l|c|c|c|c|c|}
\hline No. & Model & Option I & Option II & Option III & Reference value \\
\hline 1 & F-S-B & $6.76(5)$ & $7.92(5)$ & $8.41(5)$ & $21.89(5)$ \\
\hline 2 & I-S-B & $44.09(2)$ & $58.66(2)$ & $59.39(2)$ & $58.64(2)$ \\
\hline
\end{tabular}


Table 4. Third normal mode frequency $[\mathrm{Hz}]$

\begin{tabular}{|l|c|c|c|c|c|}
\hline No. & Model & Option I & Option II & Option III & $\begin{array}{c}\text { Reference } \\
\text { value }\end{array}$ \\
\hline 1 & F-S-B & $8.70(6)$ & $10.35(7)$ & $10.40(6)$ & $22.67(6)$ \\
\hline 2 & I-S-B & $92.89(3)$ & $112.31(3)$ & $144.95(3)$ & $112.54(5)$ \\
\hline
\end{tabular}

a)

b)

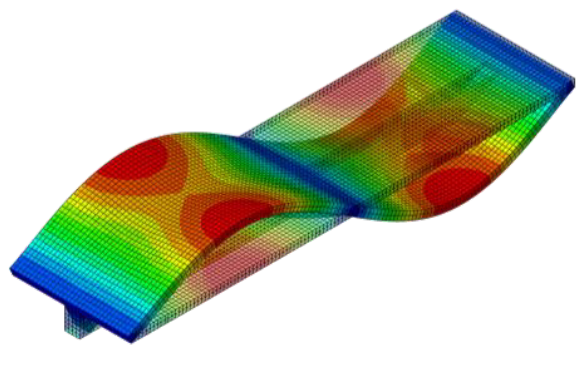

Fig. 10. Second normal mode a) I-S-B model (option I), b) S-I model deformation

Table 5. Normal mode frequencies of I-B model [Hz]

\begin{tabular}{|l|c|c|c|c|}
\hline No. & Model & First & Second & Third \\
\hline 1 & Analytical & 16.30 & 65.23 & 146.78 \\
\hline 2 & FEM & 16.31 & 64.85 & $144.95(4)$ \\
\hline
\end{tabular}

a)

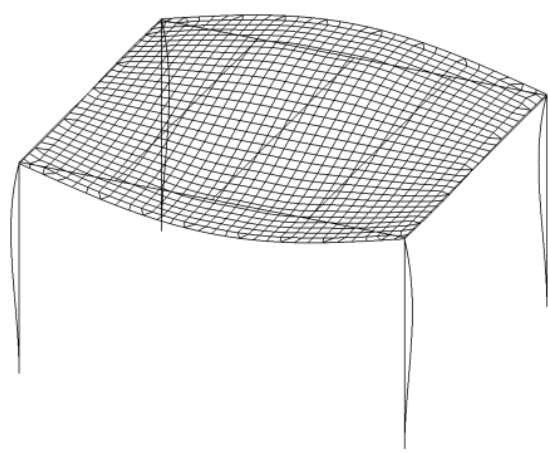

b)

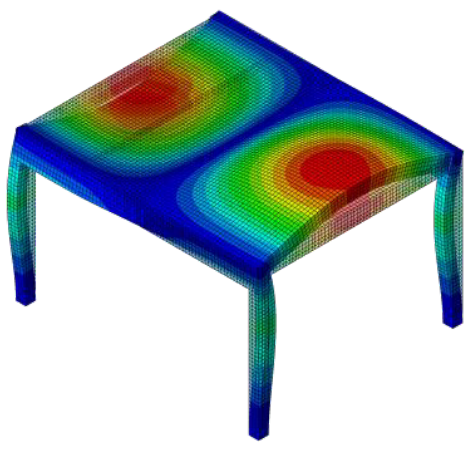

Fig. 11. Second normal mode a) F-S-B model (option I), b) S-F model deformation

\section{Conclusion}

In static analysis, computational models F-S-B and I-S-B in option I (axial beam to slab position) generates significantly different results according to other options (up to $90 \%$ differences). Models with offsets give results close to reference values, although from authors experience, it is impossible to predict, which offset option will give best results.

It has to be mentioned, that offset generates membrane forces in slab and axial forces in beam, what implies changes in required reinforcement calculations. 
Modal analysis reveals high incompatibilities between models. Twice or three times higher value indicates incorrect modelling of the structure containing both beam and shell type of elements.

\section{References}

1. Z. Kacprzyk, BIM in structural modeling and calculations, Theoretical Foundations of Civil Engineering. Structural Mechanics, VII, Oficyna Wydawnicza Politechniki Warszawskiej, Warsaw, pp. 9-20, (2016)

2. Z. Kacprzyk, B. Pawłowska, Komputerowe Wspomaganie Projektowania. Wstep $i$ przykłady, Oficyna Wydawnicza Politechniki Warszawskiej, Warszawa (2013)

3. Z. Kacprzyk, G. Rakowski, Metoda elementów skończonych w mechanice konstrukcji, Oficyna Wydawnicza Politechniki Warszawskiej, Warszawa (2005) 